\title{
Risk Evaluation and Management
}


CONTEMPORARY ISSUES IN RISK ANALYSIS

Sponsored by the Society for Risk Analysis

Volume 1 RISK EVALUATION AND MANAGEMENT

Edited by Vincent T. Covello, Joshua Menkes, and Jeryl Mumpower 


\section{Risk Evaluation and Management}

Edited by

Vincent T. Covello

and

Joshua Menkes

National Science Foundation

Washington, D.C.

and

Jeryl Mumpower

State University of New York at Albany

Albany, New York

Plenum Press • New York and London 
Risk evaluation and management.

(Contemporary issues in risk analysis; v. 1)

Includes bibliographies and index.

1. Technology assessment. 2. Risk. I. Covello, Vincent T. II. Menkes, Joshua. III. Mumpower, Jeryl, 1949- . IV. Series.

T174.5.R56 1986

(C) 1986 Plenum Press, New York

Softcover reprint of the hardcover 1st edition 1986

A Division of Plenum Publishing Corporation

233 Spring Street, New York, N.Y. 10013

All rights reserved

No part of this book may be reproduced, stored in a retrieval system, or transmitted in any form or by any means, electronic, mechanical, photocopying, microfilming, recording, or otherwise, without written permission from the Publisher 


\section{Contributors}

Michael S. Baram School of Public Health and School of Law, Boston University, Boston, Massachusetts 02118

David M. Buss Department of Psychology, University of Michigan, Ann Arbor, Michigan 48109

P. Collins Clark University, Worcester, Massachusetts 01610

Vincent T. Covello Division of Policy Research and Analysis, Policy Sciences Section, National Science Foundation, Washington, D.C. 20550

Kenneth H. Craik Institute of Personality Assessment and Research, University of CaliforniaBerkeley, Berkeley, California 94720

Karl M. Dake Institute of Personality Assessment and Research, University of CaliforniaBerkeley, Berkeley, California 94720

Donald R. DeLuca The Roper Center, Yale University, New Haven, Connecticut 06510

Lynn D. Disney Department of Environmental and Occupational Health, University of Michigan, Ann Arbor, Michigan 48109

James S. Dyer Management Department, The University of Texas, Austin, Texas 78712

Karen S. East Department of Environmental and Occupational Health, University of Michigan, Ann Arbor, Michigan 48109

Ward Edwards Social Science Research Institute, University of Southern California, Los Angeles, California 90089

John A. Ferejohn Department of Political Science, Stanford University, Palo Alto, California 94305

Baruch Fischhoff Decision Research, a branch of Perceptronics, Eugene, Oregon 97401

R. Goble Clark University, Worcester, Massachusetts 01610

A. Goldman Clark University, Worcester, Massachusetts 01610

John D. Graham Harvard School of Public Health, Boston, Massachusetts 02115

C. Hohenemser Clark University, Worcester, Massachusetts 01610

Wendy Horowitz The Roper Center, Yale University, New Haven, Connecticut 06510

Martin V. Jones Impact Assessment Institute, Rockville, Maryland 20850 
Richard M. Jones Impact Assessment Institute, Rockville, Maryland 20850

J. X. Kasperson Clark University, Worcester, Massachusetts 01610

R. E. Kasperson Clark University, Worcester, Massachusetts 01610

R. W. Kates Clark University, Worcester, Massachusetts 01610

Ralph L. Keeney Systems Science Department, University of Southern California, Los Angeles, California 90089

Michael E. Kraft Department of Public and Environmental Administration, University of Wisconsin, Green Bay, Wisconsin 54301

Lester B. Lave Graduate School of Industrial Administration, Carnegie-Mellon University, Pittsburgh, Pennsylvania 15213

Edward W. Lawless Environmental Systems Department, Midwest Research Institute, Kansas City, Missouri 64110

M. Layman Decision Research, a branch of Perceptronics, Eugene, Oregon 97401

Sarah Lichtenstein Decision Research, a branch of Perceptronics, Eugene, Oregon 97401

Douglas MacLean Center for Philosophy and Public Policy, University of Maryland, College Park, Maryland 20742

Miley W. Merkhofer Applied Decision Analysis, Inc., Menlo Park, California 94025

J. Raymond Miyares School of Public Health and School of Law, Boston University, Boston, Massachusetts 02118

Jeryl Mumpower Department of Public Administration, State University of New York at Albany, Albany, New York 12222

David Okrent Department of Mechanical, Aerospace, and Nuclear Engineering, University of California at Los Angeles, Los Angeles, California 90024

Arthur Oleinick Department of Environmental and Occupational Health, University of Michigan, Ann Arbor, Michigan 48109

R. Talbot Page Environmental Quality Laboratory, California Institute of Technology, Pasadena, California 91125

Lloyd L. Philipson $\quad$ J. H. Wiggins Company, Redondo Beach, California 90277

Howard Raiffa Harvard Business School, Cambridge, Massachusetts 02138

Rakesh K. Sarin Graduate School of Management, The University of California-Los Angeles, Los Angeles, California 90024

Kristin Shrader-Frechette Department of Philosophy, University of Florida, Gainesville, Florida 32611

Paul Slovic Decision Research, a branch of Perceptronics, Eugene, Oregon 97401

Jan A. J. Stolwijk The Roper Center, Yale University, New Haven, Connecticut 06510

James W. Vaupel Hubert Humphrey School of Public Affairs, University of Minnesota, Minneapolis, Minnesota 55455

Detlof von Winterfeldt Social Science Research Institute, University of Southern California, Los Angeles, California 90089

Marx W. Wartofsky Department of Philosophy, Baruch College, City University of New York, New York, New York 10010

Rae Zimmerman Graduate School of Public Administration, New York University, New York, New York 10003 


\section{Preface}

Public attention has focused in recent years on an array of technological risks to health, safety, and the environment. At the same time, responsibilities for technological risk assessment, evaluation, and management have grown in both the public and private sectors because of a perceived need to anticipate, prevent, or reduce the risks inherent in modern society. In attempting to meet these responsibilities, legislative, judicial, regulatory, and private sector institutions have had to deal with the extraordinarily complex problems of assessing and balancing risks, costs, and benefits.

The need to help society cope with technological risks has given rise to a new intellectual endeavor: the social and behavioral study of issues in risk evaluation and risk management. The scope and complexity of these analyses require a high degree of cooperative effort on the part of specialists from many fields. Analyzing social and behavioral issues requires the efforts of political scientists, sociologists, decision analysts, management scientists, economists, psychologists, philosophers, and policy analysts, among others.

Papers by authors from each of these disciplines are included in this volume. The papers share a focus on one or more of the following questions that are generic to the social and behavioral study of risk:

1. How do we determine how safe is safe enough?

2. How good are the knowledge base and methods for estimating the risks associated with different technologies?

3. How are estimates of risk incorporated into decision making?

4. How do decision makers treat uncertainties associated with different risks and hazards?

5. How do features of the institutional context affect decision-making bodies concerned with risk and uncertainty?

6. What factors influence individual perceptions of risk?

7. How are perceptions of risk and benefit incorporated into public policies?

8. How does society cope with risks that are unacceptable to some segments of the population?

9. How are normative considerations such as equity and social justice balanced in decision making about risk?

10. What are the criteria for comparing and evaluating different risk management policies? 
All contributions to this volume were supported in whole or part by grants from the National Science Foundation's Division of Policy Research and Analysis. Additional support for selected papers was provided by the Russell Sage Foundation. The opinions expressed in the papers are solely those of the authors and do not necessarily represent the views of the National Science Foundation or any other funding agency or source of support.

Washington, D.C.

Vincent T. Covello

Joshua Menkes

Jeryl L. Mumpower 


\section{Contents}

I. PUBLIC PERCEPTIONS OF RISK ........................ 1

1. The Psychometric Study of Risk Perception ................. 3

Paul Slovic, Baruch Fischhoff, and Sarah Lichtenstein

2. Public Perceptions of Technological Risks:

A Methodological Study .......................... 25

Donald R. DeLuca, Jan A. J. Stolwijk, and Wendy Horowitz

3. Public Disputes about Risky Technologies:

Stakeholders and Arenas .................................. 69

Ward Edwards and Detlof von Winterfeldt

4. Contemporary Worldviews and Perception of the Technological

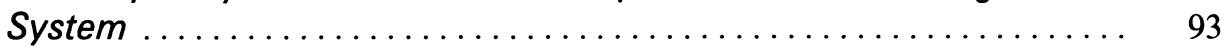

David M. Buss, Kenneth H. Craik, and Karl M. Dake

5. Risk, Relativism, and Rationality $\ldots \ldots \ldots \ldots \ldots \ldots \ldots \ldots \ldots \ldots \ldots \ldots$

Marx W. Wartofsky

II. RISK EVALUATION METHODS ..................... 155

6. Methods for Comparing the Risks of Technologies ........... 157

Edward W. Lawless, Martin V. Jones, and Richard M. Jones

7. Comparative Analysis of Formal Decision-Making Approaches .... 183 Miley W. Merkhofer

8. Measuring Risk Attitudes in Risk Analysis ................. 221

James S. Dyer and Rakesh K. Sarin 
9. The Analysis of Risks of Fatalities ... . . . . . . . . . . . . . 23.3 Ralph L. Keeney

10. Methods for Analyzing and Comparing Technological Hazards ... 249 C. Hohenemser, R. Goble, J. X. Kasperson, R. E. Kasperson, R. W. Kates,

P. Collins, A. Goldman, P. Slovic, B. Fischhoff, S. Lichtenstein, and M. Layman

11. Risk-Cost-Benefit Methodology and Equal Protection Kristin Shrader-Frechette

12. Improving Risk Analysis

R. Talbot Page and John A. Ferejohn

13. Risk Evaluation: A Review of the Literature Lloyd L. Philipson

14. Alternatives to Government Regulation for the Management of Technological Risks

Michael S. Baram and J. Raymond Miyares

15. Alternative Risk Management Policies for State and Local Governments

David Okrent

16. Institutional Mechanisms for Converting Sporadic Agency Decisions into Systematic Risk Management Strategies: OSHA, the Supreme Court, and the Court of Appeals for the District of Columbia Arthur Oleinick, Lynn D. Disney, and Karen S. East

17. The Political and Institutional Setting for Risk Analysis Michael E. Kraft

18. The Management of Risk Rae Zimmerman

19. Approaches to Risk Management: A Critique Lester B. Lave

20. Consent and the Justification of Risk Analysis Douglas MacLean 
IV. OVERVIEW OF RISK EVALUATION MANAGEMENT ........... 501

21. Science and Analysis: Roles in Risk and Decision Making ...... 503 John D. Graham, Howard Raiffa, and James W. Vaupel

22. Risk Analysis and Risk Management: A Historical Perspective ... 519 Vincent T. Covello and Jeryl Mumpower 